OPEN ACCESS

Edited by: Elia Valentini, University of Essex, United Kingdom

Reviewed by:

Daniel Fiset,

Université du Québec en Outaouais,

Canada

Annick Lena De Paepe,

Ghent University, Belgium

*Correspondence:

Paola Sessa

paola.sessa@unipd.it

Specialty section: This article was submitted to

Perception Science,

a section of the journal

Frontiers in Psychology

Received: 29 April 2018 Accepted: 07 September 2018 Published: 11 October 2018

Citation:

Schiano Lomoriello A, Meconi F, Rinaldi I and Sessa P (2018) Out of Sight Out of Mind: Perceived

Physical Distance Between the Observer and Someone in Pain Shapes Observer's Neural Empathic Reactions. Front. Psychol. 9:1824. doi: 10.3389/fpsyg.2018.01824

\section{Out of Sight Out of Mind: Perceived Physical Distance Between the Observer and Someone in Pain Shapes Observer's Neural Empathic Reactions}

\author{
Arianna Schiano Lomoriello', Federica Meconi' ${ }^{2}$, Irene Rinaldi' and Paola Sessa ${ }^{1,3 *}$ \\ ${ }^{1}$ Department of Developmental and Social Psychology, University of Padova, Padova, Italy, ${ }^{2}$ School of Psychology, \\ University of Birmingham, Birmingham, United Kingdom, ${ }^{3}$ Padova Neuroscience Center (PNC), University of Padova, \\ Padova, Italy
}

Social and affective relations may shape empathy to others' affective states. Previous studies also revealed that people tend to form very different mental representations of stimuli on the basis of their physical distance. In this regard, embodied cognition and embodied simulation propose that different physical distances between individuals activate different interpersonal processing modes, such that close physical distance tends to activate the interpersonal processing mode typical of socially and affectively close relationships. In Experiment 1, two groups of participants were administered a pain decision task involving upright and inverted face stimuli painfully or neutrally stimulated, and we monitored their neural empathic reactions by means of event-related potentials (ERPs) technique. Crucially, participants were presented with face stimuli of one of two possible sizes in order to manipulate retinal size and perceived physical distance, roughly corresponding to the close and far portions of social distance. ERPs modulations compatible with an empathic reaction were observed only for the group exposed to face stimuli appearing to be at a close social distance from the participants. This reaction was absent in the group exposed to smaller stimuli corresponding to face stimuli observed from a far social distance. In Experiment 2, one different group of participants was engaged in a match-to-sample task involving the two-size upright face stimuli of Experiment 1 to test whether the modulation of neural empathic reaction observed in Experiment 1 could be ascribable to differences in the ability to identify faces of the two different sizes. Results suggested that face stimuli of the two sizes could be equally identifiable. In line with the Construal Level and Embodied Simulation theoretical frameworks, we conclude that perceived physical distance may shape empathy as well as social and affective distance.

Keywords: empathy, physical distance, construal level theory, embodiment, event-related potentials 


\section{INTRODUCTION}

Humans are endowed with an extraordinary ability to share and understand the affective states of others, and this is vital as it allows appropriate social interactions and relationships with others. This ability, known as empathy, is multifaceted since consisting of several aspects, including emotion contagion, empathic accuracy, concern for others, self-other distinction, emotion regulation and perspective taking (Preston and de Waal, 2002; Decety and Jackson, 2004, 2006; Zaki and Ochsner, 2012).

The present investigation aimed at exploring whether the physical distance between an observer and an individual in a particular affective state (induced by a painful stimulation) is a critical factor in modulating the magnitude of an empathic neural reaction in the observer.

In the field of social and affective neuroscience, investigation has indeed mostly focused on empathy toward others' pain (Astolfi et al., 2005; Singer et al., 2006; Decety and Lamm, 2007; Fan and Han, 2008; Li and Han, 2010; Sheng and Han, 2012; Sessa et al., 2014a; Meconi et al., 2015; Sessa and Meconi, 2015; Sheng et al., 2016). In this context, most of the proposed theoretical frameworks have conceived empathy as comprised of at least two components, widely independent and dissociable, both functionally and anatomically (Decety and Lamm, 2007; Zaki and Ochsner, 2012; Sessa et al., 2014b). One of the components is termed affective empathy or experience sharing - mainly based on neural resonance mechanisms - and the other component is termed cognitive empathy - mainly based on mental state attribution ability (Decety and Lamm, 2007; Zaki and Ochsner, 2012; Zaki, 2013). Notably, this functional distinction corresponds to an anatomical dissociation such that affective empathy has its neural substrate in regions previously associated with the mirror neuron system (premotor cortex and inferior parietal lobule) and with the limbic system (anterior cingulate cortex and anterior insula), while the neural underpinnings of the cognitive component of empathy, related to mentalizing, are in regions associated with the Theory of Mind, including medial prefrontal cortex, temporal poles, precuneus and temporo-parietal junction (see Zaki and Ochsner, 2012; see also, e.g., Saxe and Kanwisher, 2003; Amodio and Frith, 2006; Shamay-Tsoory et al., 2009; Lamm and Singer, 2010; Rizzolatti and Sinigaglia, 2010; Decety, 2011; Fan et al., 2011).

A notable aspect of the human ability to experience empathy toward other people's affective states and emotions is that it may be shaped by a variety of factors, including the characteristics of the observer and those of the individual experiencing a particular affective condition (Davis, 1983; Blair, 2005; Dapretto et al., 2006; Harris and Fiske, 2006; Hein et al., 2010; Wagner et al., 2011; Philip et al., 2012) or also the affective and social relationship existing between the observer and the other individual, such that at least part of the brain network underlying empathy (i.e., anterior cingulate cortex and anterior insula) is strongly activated in those cases when the partner, rather than a stranger, is experiencing a pain stimulation (Singer et al., 2004), or in cases when the other is an individual with whom the observer has established a relationship of trust rather than distrust (Singer et al., 2006), or when the individual experiencing pain belongs to the observer's ethnic group rather than a different ethnic group (Xu et al., 2009; Avenanti et al., 2010; Contreras-Huerta et al., 2013, 2014; Sessa et al., 2014a). In brief, the chance that an empathic reaction will be triggered and its magnitude depend on the nature of the social and affective relationships that binds people.

Interestingly, social and affective relationships are often designated in terms of "distance," and just as for the physical distance, the terms "close" and "distant" tend to be used in the context of relationships, for example, associating them with an intimate friend or with a relative almost unknown to us, respectively (Lakoff and Johnson, 1980; Lakoff and Mark, 1999). In this vein, it is possible to conceive social and affective relationships between individuals as if they were mapped onto a sort of virtual space. Support in favor of this proposal comes, for instance, from a functional magnetic resonance imaging (i.e., fMRI) study by Yamakawa et al. (2009) who asked their participants, in two different tasks, to evaluate social compatibility with presented individuals' faces and to evaluate physical distance of inanimate objects. The rationale for the implementation of these two tasks was that if evaluation of both psychological and physical distances has a common functional and neural substrate, one would expect to observe an overlapping activation in those brain regions involved in the representation of the egocentric physical space (Roland et al., 1980; Sakata et al., 1980; Rapcsak et al., 1995; Neggers et al., 2006; Naito et al., 2008). In line with this hypothesis, Yamakawa et al. (2009) findings provided evidence in favor of the existence of a common neural substrate in the parietal cortex for both mental representations of social relationships and physical space.

Further supporting the view that physical and psychological spaces are inextricably linked, is the observation, now dating back over 50 years, that the distance between individuals varies as a function of their intimacy (see e.g., Hall, 1966, 1969). One of the most interesting and fundamental pillars of Proxemics - the study of personal space (Argyle and Dean, 1965; Hall et al., 1968; Hayduk, 1983) indicates that people unconsciously organize the space around them in concentric areas, so that the areas closest to one's body are the privileged space of action(s) for the most intimate interactions, and, conversely, the areas most distant from the body are mostly associated with the space of action(s) for interactions with individuals with whom they share a low degree of intimacy. These concentric "virtual" zones around the individual's body may vary according to different factors, such as the culture or the gender of the individuals, but the general principle according to which a relationship exists between the degree of intimacy between two individuals and the physical distance that tends to settle during their interaction is a constant element independent of other factors (Hall, 1966).

These considerations on the direct relationship between physical and psychological distance led us to hypothesize that empathy toward others' pain could be modulated also on the basis of the physical distance between the observer and the individual 
subjected to a pain stimulation, just as happens for the social and affective distance (Singer et al., 2004, 2006; Xu et al., 2009; Avenanti et al., 2010; Sessa et al., 2014a).

In order to test this hypothesis, in Experiment 1 two groups of participants were administered a pain decision task (Xu et al., 2009; Sessa et al., 2014a,b) in which faces (either upright or inverted) were presented in two different experimental conditions, i.e., pricked by a syringe (pain condition) or touched by a Q-tip (neutral condition), while participants' electroencephalogram (EEG) was recorded. Participants' task was to decide whether each face was painfully or neutrally stimulated. Importantly, the two groups of participants were presented with face stimuli of one of two possible sizes in order to manipulate the retinal size and therefore the perceived physical distance (see, e.g., Gogel, 1998), which approximately corresponded to close (6.56 feet, $\sim 2 \mathrm{~m} /$ close social distance) and far (9.84 feet, $\sim 3 \mathrm{~m} /$ far social distance) portions of the social distance (Hall, 1966). The choice to select these two specific perceived distances was based on the organization of the concentric "virtual" zones identified by the Proxemics. In particular, we decided to choose distances that were attributable to the "zone" ascribed to the "social distance" as identified by Hall (1963). This zone is located beyond the personal space that is reserved for more or less intimately known people, and is instead reserved for strangers, people one has just met and acquaintances. Since the faces that participants observed in this study were all of strangers, we considered it more appropriate from an ecological point of view that they were presented within the social distance zone. Furthermore, we have avoided presenting faces at a perceived distance corresponding to the personal space since it is known that, when this space is invaded, affective states that are in contrast with a possible empathic reaction may occur in the observer, such as anxiety, distress or anger (Hall, 1969). The social distance, on the other hand, permits interaction with others, but allows at the same time the individual to feel safe. It is important to add that this social distance zone can be in turn divided into two different portions or phases affecting the (potential) interaction with others, one corresponding to the close social space (within 7 feet or $2.1 \mathrm{~m}$ ) and one corresponding to the far social space (over 7 feet, and up to about 12 feet or $3.7 \mathrm{~m}$ ). Therefore, in line with this body of knowledge, we decided to use two sizes of face stimuli corresponding to perceived distances within the close social zone and within the distant social zone.

We adopted a minimalist experimental manipulation to induce different perceived distances of the face stimuli in order to keep stimulation as similar as possible to that usually employed in the standard pain decision task, and to limit the introduction of confounding elements, as for example other stimuli in the visual scene in addition to the empathy-related stimuli, possibly able to affect event-related potentials (ERPs) in unpredictable ways. On the other hand, if an object's size is known, as for faces, its retinal image can be used to judge its distance (see, e.g., Gogel, 1998).

The usually observed ERPs modulations observed in the pain decision task involve a shift toward more positive values for the pain condition than the neutral condition of a subset of ERPs components ranging from the $\mathrm{P} 2$ to the $\mathrm{P} 3 / \mathrm{LPP}$ components recorded at both frontal and parietal electrode sites (Sessa and Meconi, 2015; Sheng et al., 2016; see also, e.g., Donchin, 1981; Donchin and Coles, 1988; Verleger, 1988; Sessa et al., 2007). An ERP empathic reaction is defined by the difference between $\operatorname{ERP}(\mathrm{s})$ elicited in the pain and in the neutral conditions (Fan and Han, 2008; Decety et al., 2010; Li and Han, 2010; Sheng and Han, 2012; Sessa et al., 2014a,b). In Experiment 1 , we expected to observe a moderating effect on empathic ERP reactions as a function of the perceived physical distance of the faces, such that the group of participants exposed to faces perceived as more distant would have manifested a lower magnitude of these neural empathic reactions when compared to the group of participants exposed to faces perceived as closer. We hypothesized that inverted faces would not have induced an empathic reaction because of the disruption of the configural/holistic processing (Leder and Bruce, 2000) in either groups of participants. For this reason we expected reduced if null empathic reactions for inverted faces for both groups of participants. In this vein, we considered the inverted face condition that served as a control for other possible intervening factors in modulating ERPs. However, to our knowledge this is the first study investigating whether inverted faces painfully or neutrally stimulated may induce or not empathic reactions, therefore this aspect of the present study was purely exploratory.

We further designed a second experiment (Experiment 2) to test whether possible modulations of the neural empathic reactions in Experiment 1 could be ascribable to differences in the ability to identify faces of the two different sizes. In order to investigate this possibility, in Experiment 2, a new group of participants was engaged in a behavioral match-to-sample task involving the two-size upright face stimuli of Experiment 1.

\section{EXPERIMENT 1}

\section{Method \\ Participants}

Before starting data collection, we established to enter into ERP analyses data from 15 to 20 participants for each of the two experimental groups because of existing literature in this field that suggests it is an appropriate sample (Fan and Han, 2008; Sheng and Han, 2012). Analyses were conducted only after data collection was complete. Data were then collected from 40 volunteer healthy students (11 males) from the University of Padova. Data from 7 participants were excluded from the analyses due to excessive electrophysiological artifacts, of which 17 for one group and 16 for the other group. For this reason an additional participant was tested such that the two groups had the same number of participants. All participants reported normal or corrected-to-normal vision and normal audition and no history of neurological disorders. They were randomly assigned to the two different groups, as a function of the two different physical sizes of face stimuli. Each group included 17 participants (for far physical distance: 5 males; mean age: 23.8 years, $S D=4.28$, 4 lefthanded; for close physical distance: 6 males, mean age: 23.2 years, $S D=3.62,4$ left-handed). All participants signed a consent form 
according to the ethical principles approved by the University of Padova.

\section{Stimuli}

The stimuli were 12 digital photographs of White faces with a neutral facial expression from the Eberhardt Lab Face Database (Mind, Culture, \& Society Laboratory at Stanford University) ${ }^{1}$. Each face was digitally manipulated in order to obtain stimuli for two different stimulation conditions, one in which faces received a painful stimulation (needle of a syringe penetration), and one in which faces received a neutral (Q-tip touch) stimulation (applied either to the left or to the right cheek).

All faces were presented in the upright and inverted orientation and in two different physical sizes, in order to manipulate retinal size and perceived physical distance, both beyond the intimate and personal distances, and roughly corresponding to the close and far portions of social distance (Hall, 1966). Face stimuli appearing to be in the far portion of social distance fit in $1.6^{\circ} \times 2.5^{\circ}$ (width $\times$ height), whereas face stimuli appearing in the close portion of social distance fit in $2.5^{\circ} \times 3.3^{\circ}$ (width $\times$ height). One group was exposed to faces appearing to be distant from participants 6.56 feet $(\sim 2 \mathrm{~m}$; close social distance) and the other group was exposed to faces appearing to be distant from participants 9.84 feet $(\sim 3 \mathrm{~m}$; far social distance). Stimuli were presented on a 17 -in cathode ray tube monitor controlled by a computer running E-prime software.

\section{Experimental Design}

We implemented a variant of the pain decision task. Each trial began with the presentation of a fixation cross at the center of the screen (800-1600 ms, jittered in steps of $100 \mathrm{~ms})$, followed by a face displayed for $400 \mathrm{~ms}$. The sequence of events of each trial is depicted in Figure 1. Please note that the original face stimuli have been replaced in Figures 1A,B with other face stimuli not belonging to the Eberhardt Lab Face Database according to the terms of use of the Database.

Participants were instructed to decide whether each face was painfully or neutrally stimulated by pressing one of two appropriately labeled keys of the computer keyboard as quickly and accurately as possible. Following a brief session of practice in order to familiarize with the task, participants performed 576 trials divided in 4 blocks (144 trials for each block including all the possible experimental combinations, intermixed within each block). Participants could manage a break session between a block and the next block of trials and decided when to continue by pressing the space bar. The experiment lasted for approximately 30-40 min. The entire experimental session, including the preparation of the participant for the EEG data collection, lasted about 60-75 $\mathrm{min}$.

\section{Electrophysiological Recording and Analyses}

The EEG was recorded from 64 active electrodes distributed over the scalp in accordance with the international 10/20 system placed on an elastic Acti-Cap, referenced to the left earlobe. The

${ }^{1}$ http://www.stanford.edu/group/mcslab/cgi-bin/wordpress/examine-theresearch/
EEG was re-referenced offline to the average of the left and right earlobes. Horizontal EOG (i.e., HEOG) was recorded bipolarly from two external electrodes positioned laterally to the left and right external canthi. Vertical EOG (i.e., VEOG) was recorded from Fp1 and one external electrode placed below the left eye. The electrode impedance was kept less than $10 \mathrm{~K} \Omega$ because of the highly viscous electro-gel and the properties of active electrodes. Offline EEG processing and analyses were conducted using Brain Vision Analyzer software (Brain Products) ${ }^{2}$.

EEG, HEOG, and VEOG signals were amplified (pass band $0.01-80 \mathrm{~Hz}$ ) and digitized at a sampling rate of $250 \mathrm{~Hz}$. The EEG was segmented into $1200 \mathrm{~ms}$ epochs starting $200 \mathrm{~ms}$ prior to the onset of the faces. The epochs were baseline-corrected based on the mean activity during the $200 \mathrm{~ms}$ pre-stimulus period, for each electrode site. Trials associated with incorrect responses or contaminated by large horizontal eye movements, eye blinks or other artifacts (exceeding $\pm 30 \mu \mathrm{V}, \pm 60 \mu \mathrm{V}$, and $\pm 80 \mu \mathrm{V}$, respectively) were automatically discarded from analysis, which accounted for the exclusion of an average of $6 \%$ of trials. Separate average waveforms for each condition were then generated time-locked to the presentation of the face stimuli for each experimental condition. Statistical analyses of ERPs mean amplitudes focused on a time window ranging from 300 and $600 \mathrm{~ms}$, corresponding to the P3 ERP component. Mean P3 amplitude values were measured at pooled electrode sites selected from fronto-central (Fz, F1, F2, F3, F4, F5, F6, FCz, FC1, FC2, FC3, FC4, FC5, FC6) and centro-parietal $(\mathrm{CPz}, \mathrm{CP} 1, \mathrm{CP} 2, \mathrm{CP} 3$, CP4, CP5, CP6, Pz, P1, P2, P3, P4, P5, P6) electrodes according to visual inspection and previous work (Fan and Han, 2008; Sessa et al., 2014a,b; Meconi et al., 2015; Sessa and Meconi, 2015).

\section{Behavioral and ERPs Results}

The significant threshold for all statistical analyses was set to.05. Exact $p$-values and effect sizes (i.e., partial eta-squared, $\eta_{p}^{2}$ ) are reported. Planned comparisons relevant to test the hypotheses of the present experiment are reported.

\section{Behavioral results}

Individual mean proportion of correct responses was submitted to a mixed analysis of variance (ANOVA), considering stimulation of face stimuli (painfully vs. neutrally stimulated) and orientation (upright vs. inverted) as within-subjects factors and physical distance (far social distance vs. close social distance) as a between-subjects factor. The main effect of neither face stimuli or orientation were significant [respectively: $F<1$, $\left.p=0.970, \eta_{\mathrm{p}}^{2}=0.000 ; F(1,32)=3.679, p=0.064, \eta_{\mathrm{p}}^{2}=0.103\right]$; the mean proportion of correct responses for face stimuli neutrally stimulated in the upright orientation was $0.984 ; S D=0.17$, and in the inverted orientation condition was $0.985 ; S D=0.14$; the mean proportion of correct responses for face stimuli painfully stimulated in the upright orientation was $0.985 ; S D=0.17$, and in the inverted orientation was 0.9.88; $S D=0.14$ ). The interactions between face stimuli and physical distance and between orientation and physical distance were not significant: $F<1, p=0.986, \eta_{\mathrm{p}}^{2}=0.000 ; F<1, p=0.341, \eta_{\mathrm{p}}^{2}=0.028$, respectively.

\footnotetext{
${ }^{2}$ www.brainproducts.com
} 
A

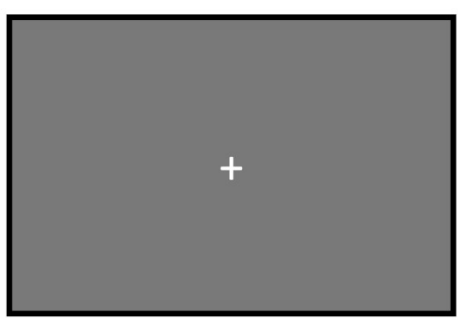

$800-1600 \mathrm{~ms}$

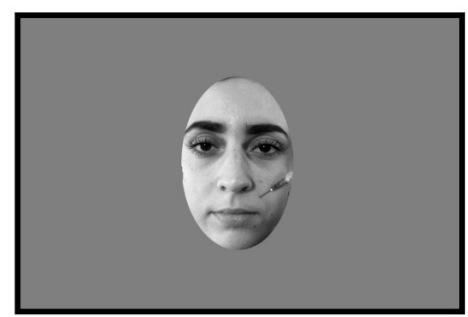

$400 \mathrm{~ms}$

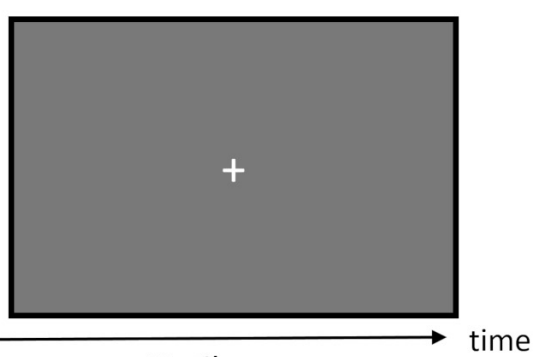

Until response time

Representation of a painfully stimulated face in the

"far social distance" condition

B

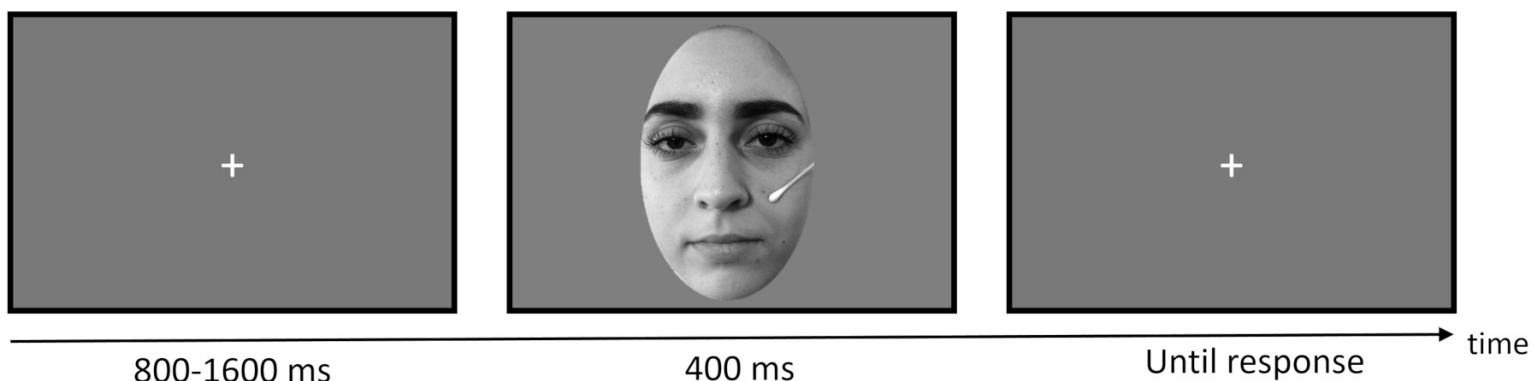

Representation of a neutrally stimulated face in the "close social distance" condition

FIGURE 1 | Timeline of each trial for Experiment 1 (pain decision task): (A) example of a trial for the far social distance condition with a painfully stimulated face; (B) example of a trial for the close social distance condition with a neutrally stimulated face. Original face stimuli have been replaced in (A,B) with actors according to the terms of use of the Eberhardt Lab Face Database.

Reaction times (RTs) exceeding each individual mean RT in a given condition $\pm 2.5 S D$ and RTs associated with incorrect responses were excluded from the RTs analysis. Individual mean proportion of correct responses and RTs were submitted to a mixed ANOVA, including face stimuli (painfully vs. neutrally stimulated) and orientation (upright vs. inverted) as withinsubjects factors and physical distance (far social distance vs. close social distance) as a between-subjects factor. None of the effects were statistically significant $(F<1 ; \min p=0.98)$.

\section{Event-related potentials}

Grand averages of the face-locked ERP waveforms elicited in the pain and neutral stimulation conditions separately for pooled fronto-central (FC) and centro-parietal (CP) electrode site and for close and far social distance are shown in Figure 2 (upright face stimuli) and Figure 3 (inverted face stimuli).

A mixed ANOVA of P3 amplitude values including stimulation of face stimuli (painfully vs. neutrally stimulated) and orientation (upright vs. inverted) as within-subjects factors and physical distance (far vs. close) as a between-subjects factor was carried out for each ERP electrodes pool.

The ANOVA revealed a significant main effect of orientation at FC pooled electrode sites, $F(1,32)=18.610, p<0.001$, $\eta_{\mathrm{p}}^{2}=0.368$, and at CP pooled electrode sites, $F(1,32)=16.908$, $\left.p=0.001, \eta_{\mathrm{p}}^{2}=0.514\right)$. The main effect of stimulation of face stimuli reached significance level only for CP pooled sites, $F(1,32)=7.950, p=0.012, \eta_{\mathrm{p}}^{2}=0.332$, (at FC pooled sites: $F<1)$. The interaction between these two factors did not reach significance level for neither of the two pooled electrode sites (FC pooled sites: $F(1,32)=1.735, p=0.206, \eta_{\mathrm{p}}^{2}=0.98$; CP pooled sites $F<1)$. Notably, the interaction between stimulation of face stimuli and physical distance reached significance both at FC pooled electrode sites, $F(1,32)=8.697, p=0.001, \eta_{p}^{2}=0.020$, and at CP pooled electrode sites, $F(1,32)=4.589, p=0.040$, $\eta_{\mathrm{p}}^{2}=0.125$. Planned comparisons revealed that for face stimuli perceived at a closer physical distance the painful condition elicited more positive P3 amplitude than the neutral condition (at FC pooled sites: $t=-3.044, p=0.008$; Mdiff $=-1.050$ $[-1.78,-3.18]$; at CP pooled sites: $t=-2.626, p=0.018$; Mdiff $=-0.915[-1.65,-0.176])$. This effect was manifest as a positive shift of the ERP activity for face stimuli painfully stimulated (at FC pooled sites $0.964 \mu \mathrm{V}, S D=2.34$; at $\mathrm{CP}$ pooled sites $4.98 \mu \mathrm{V}, S D=3.48$ ) relative to face stimuli neutrally stimulated (at FC pooled sites $-0.0862 \mu \mathrm{V}, S D=2.25$; at $\mathrm{CP}$ pooled sites $5.05 \mu \mathrm{V}, S D=3.09)$. Importantly, this positive shift indexing an empathic reaction was not observed for face stimuli appearing at far physical distance (at FC pooled sites: $t=1.056, p=0.307 ;$ Mdiff $=0.408[-0.411,1.22]$; at CP pooled 


\section{Upright face stimuli}
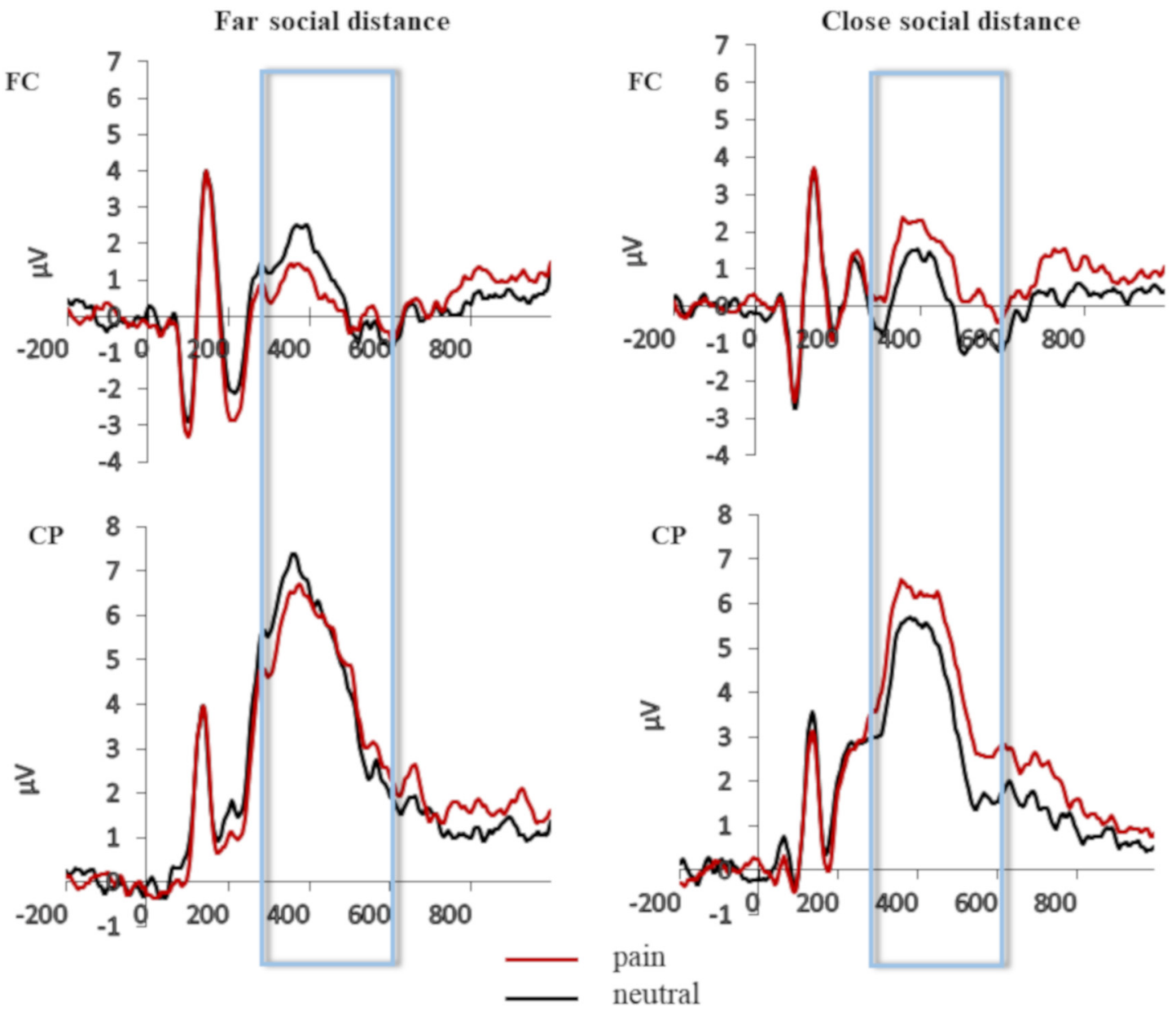

FIGURE 2 | Grand averages of the face-locked ERP waveforms for the upright face stimuli elicited in the pain and neutral stimulation conditions separately for pooled fronto-central (FC) and centro-parietal (CP) electrode site and for close and far social distance.

sites: $t=0.188, p=0.853$, Mdiff $=0.069$ [0.712,0.8516]. The interaction between orientation and physical distance and the triple interaction between stimulation of face stimuli, physical distance and orientation were not significant [at FC: both Fs $>1$; at CP: $F(1,32)=1.444, p=0.238, \eta_{\mathrm{p}}^{2}=0.043$ and $F<1$, respectively].

\section{EXPERIMENT 2}

Our experimental hypothesis on the modulating role of physical distance on empathy was corroborated, i.e., we observed greater empathic ERP reactions for the group of participants exposed to faces perceived as closer compared to the group of participants exposed to faces perceived as more distant, independently of faces orientation. As this first experiment left open the possibility that the differences observed between the two groups could depend on a different degree of discriminability of the faces perceived as closer and those perceived as more distant, we designed a second experiment (Experiment 2) to test whether the modulation of neural empathic reaction observed in Experiment 1 could be ascribable to differences in the ability to identify faces of the two different sizes. In order to investigate this possibility, in Experiment 2, a new group of participants was engaged in a behavioral match-to-sample task involving the two-size upright face stimuli of Experiment 1.

\section{Method}

\section{Participants}

Data were collected from 22 volunteer healthy students (3 males) from the University of Padova. All reported normal or corrected-to-normal vision and no history of neurological disorders. All 22 participants (3 males; mean age: 23.40 years, $S D=1.79 ; 3$ left-handed) were included in the final sample. All participants signed a consent form according to the ethical principles approved by the University of Padova. Analyses were conducted only after data collection was complete. 


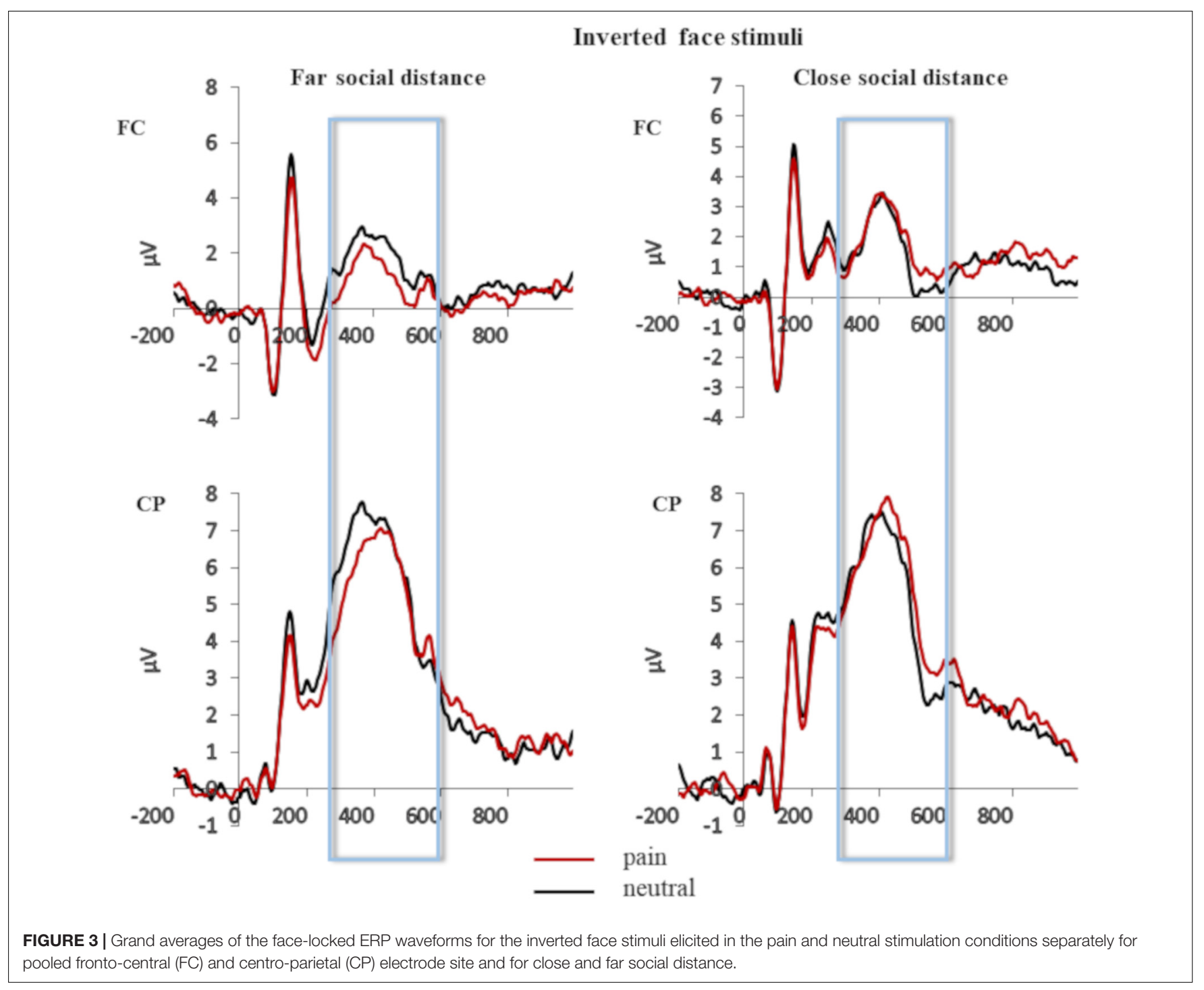

\section{Stimuli}

The stimuli were the same 12 digital photographs of White neutral faces from the Eberhardt Lab Face Database (Mind, Culture, \& Society Laboratory at Stanford University) ${ }^{3}$ used in Experiment 1 (including the painful/neutral stimulation).

All faces were presented in the two different physical sizes used in Experiment 1. Stimuli were presented on a 17-in cathode ray tube monitor controlled by a computer running E-prime software.

\section{Procedure}

\section{Experimental design}

We implemented a variant of the discrimination task based on an XAB match-to-sample task used by Newell and Bülthoff (2002; see also Young et al., 1997). On each trial a face stimulus (stimulus $\mathrm{X}$ ) was presented and then followed by two face stimuli (stimuli

${ }^{3}$ https://web.stanford.edu/group/mcslab/cgi-bin/wordpress/examine-theresearch/
A and B) presented simultaneously, one on the left and one the right of the fixation.

Each trial began with a fixation cross presented for $500 \mathrm{~ms}$. Then the first face stimulus (X) of one of the two possible sizes was shown for $750 \mathrm{~ms}$ in the center of the screen. The next pair of face stimuli (A and B), of the same size of the first face (stimulus $\mathrm{X}$ ), remained on the screen until the participant pressed a response button. Each of the A and B face stimuli were displayed $3 \mathrm{~cm}$ to the left and to the right relative to the center of the screen.

Participants were instructed to respond as fast and as accurately as possible, indicating which face stimulus of the $A B$ pair was identical to the preceding face stimulus X. Participants were instructed to press a key on the left (or on the right) of the keyboard to indicate that the face stimulus presented on the left (or on the right) was identical to the previously presented face stimulus (stimulus X). Following a brief session of practice in order to familiarize with the task, participants performed 528 trials, divided in 4 blocks (i.e., each block consisting of 132 trials). Faces of different sizes were presented in separate block 
of trials, whose order was counterbalanced between participants. Participants could manage a break session between the blocks trials and decided when to continue by pressing the space bar. The experiment lasted about $35 \mathrm{~min}$.

Figure 4 shows two examples of trials, one (a) for the far social distance condition, and the other (b) for the close social distance condition. Original face stimuli have been replaced in the Figures 4A,B with other face stimuli not belonging to the original database according to the terms of use of the Eberhardt Lab Face Database.

\section{Statistical Analysis}

The significant threshold for all statistical analyses was set to 0.05 . Exact $p$-values and effect sizes (i.e., partial eta-squared, $\eta_{p}^{2}$ ) are reported. Planned comparisons relevant to test the hypotheses of the present experiment are reported.

\section{Behavioral results}

Individual mean proportions of correct responses were submitted to a one-way ANOVA, considering physical distance (far vs. close) as a within-subjects factor. The main effect of physical distance did not approach significance level: $F(1,21)=0.236$, $p=0.632, \eta_{\mathrm{p}}^{2}=0.11$ (see Figure 5).

Reaction times exceeding each individual mean RTs in a given condition $\pm 2.5 S D$ and RTs associated with incorrect responses were excluded from the RTs analysis. RTs were submitted to a one-way ANOVA, considering physical distance (far vs. close) as a within-subjects factor. The effect of physical distance did not approach significant level: $F(1,21)=0.648, p=0.430, \eta_{\mathrm{p}}^{2}=0.030$.

\section{DISCUSSION}

A significant body of research has undoubtedly shown that the magnitude of an observer's empathic reaction depends on the social and affective bond existing with the individual experiencing an affective state in first-person (Singer et al., 2004; Rameson and Lieberman, 2009; Xu et al., 2009; Avenanti et al., 2010; Decety and Svetlova, 2012; Contreras-Huerta et al., 2013, 2014; Sessa et al., 2014a; Lockwood, 2016). Based on robust experimental evidence suggesting the existence of an inextricable link between the processing of physical distance and that of psychological distance (Hall, 1966, 1969), the present study aimed at investigating whether physical distance, like the psychological distance, could be a modulator of the magnitude of the observer's empathic reaction for an individual in a state of physical pain. In order to test this hypothesis, we implemented a between-subjects experimental design (Experiment 1) in which we manipulated the perceived physical distance (close social distance: $6.56 \mathrm{feet}, \sim 2 \mathrm{~m}$ vs. far social distance: 9.84 feet, $\sim 3 \mathrm{~m}$ ) of upright and inverted

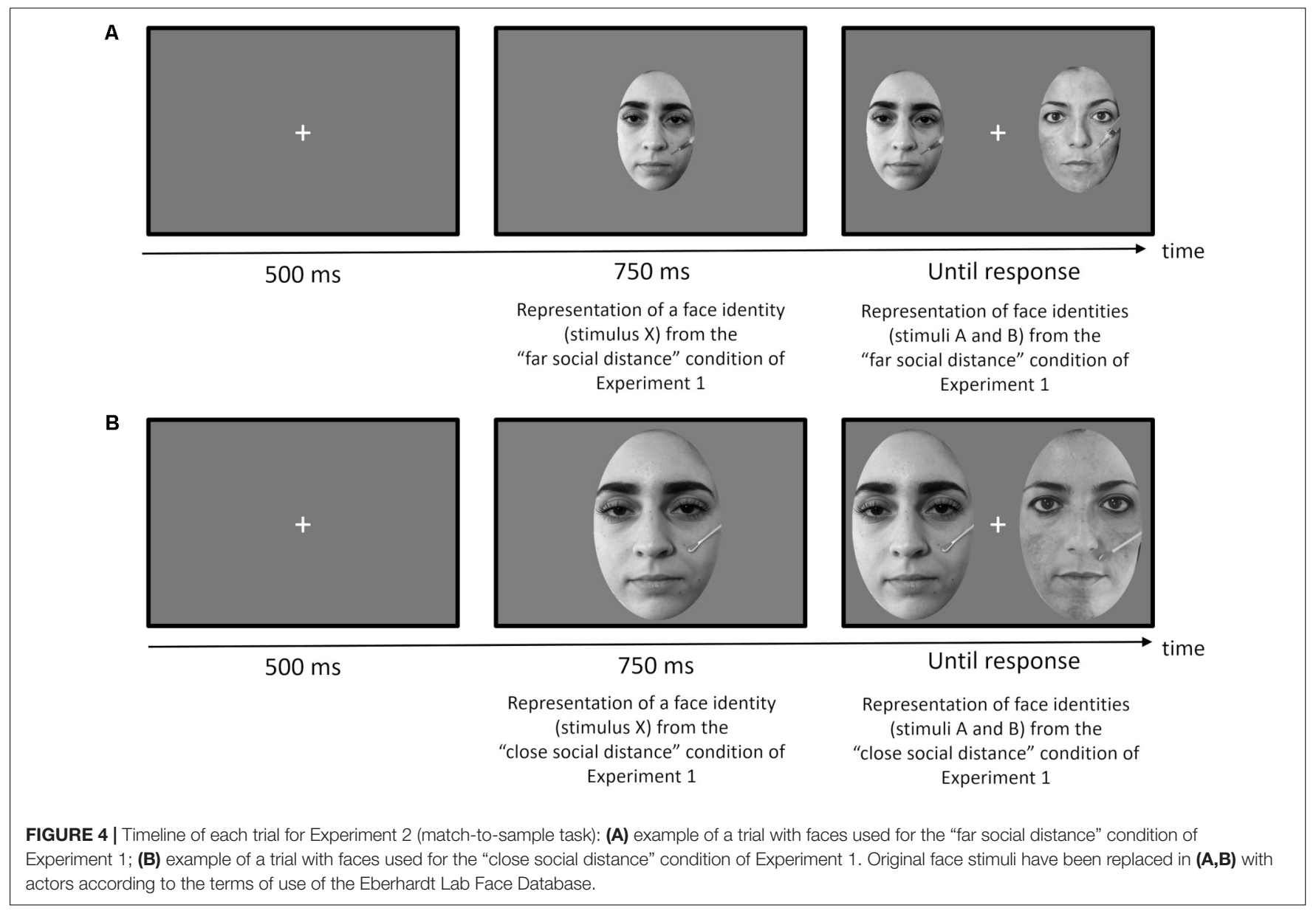




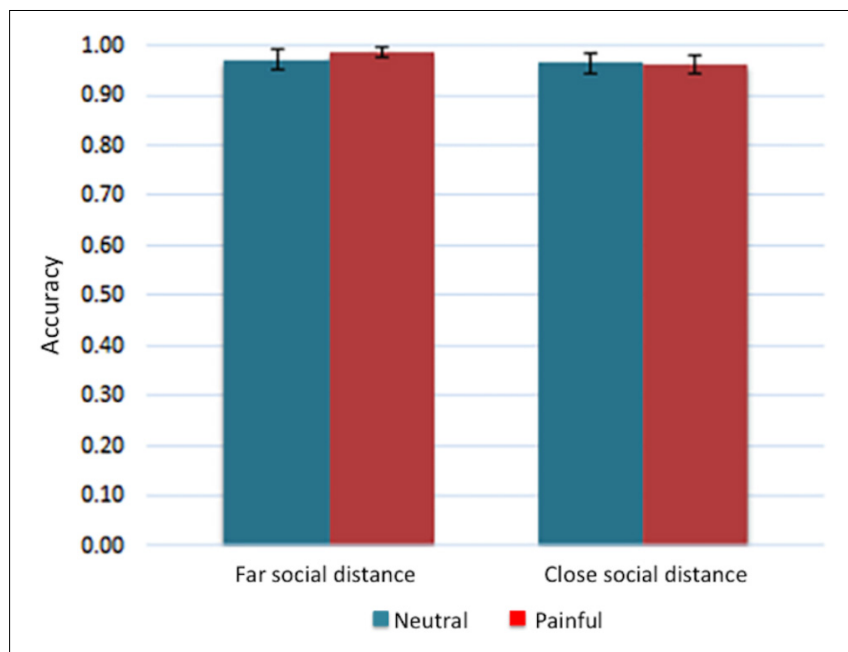

FIGURE 5 | Bar chart displaying mean rating scores for each condition for Experiment 2. Error bars represent standard errors.

faces pricked by a syringe (i.e., pain condition) or touched by a Q-tip (i.e., neutral condition). We therefore expected to observe a reduced empathic reaction in the group of participants exposed to faces perceived as more distant when compared to the empathic reaction in the group of participants exposed to faces perceived as closer. Whether this reaction could be selectively observed for upright faces was an open question. In line with this hypothesis, the results indicated that in a time window between 300 and $600 \mathrm{~ms}$ following the presentation of the face stimuli, a clear ERP pattern previously linked with an empathic reaction (e.g., Sessa et al., 2007; Sheng and Han, 2012; Meconi et al., 2015) was observed at both FC and CP regions in the group of participants exposed to the face stimuli perceived as closer, while this reaction was absent in the group of participants exposed to face stimuli perceived as more distant. This effect did not interacted with the orientation of the faces, suggesting that also inverted faces can elicit an empathic reaction. Importantly, no differences were observed in terms of accuracy in discriminating between the painful and the neutral stimulation conditions indicating that the differences in empathic reactions between the two groups of participants did not depend on differences in the ability to discriminate between the two stimulation categories (i.e., painful vs. neutral stimuli) in the two different sizes conditions, further suggesting that the observed differences in the empathic reaction depended indeed on the manipulation of perceived distance of face stimuli.

Experiment 1 did not allow us to clarify whether the modulation of the empathic reaction in the two groups depended on differences in discriminability of the faces of the two sizes. This possibility could be particularly relevant in light of the consolidated knowledge in the context of the social psychology of two possible putative cognitive operations that people use during the perception of others, i.e. individuation and categorization (see Brewer, 1988; Fiske and Neuberg, 1990). While individuation is that mechanism by which the other individual is perceived as a unique entity, the mechanism of categorization leads to others' perception based on their categorization as belonging to a specific social group. Notably, evidence in the context of empathy toward others' pain suggests that these mechanisms may be critical modulators of the empathic reaction, so that individuation favors an empathic reaction while categorization tends to be associated with its suppression (Sheng and Han, 2012). These considerations could therefore suggest that under conditions in which faces are more easily discriminable, an individuation mechanism can be favored and this in turn could promote an empathic reaction. We then implemented a second experiment (Experiment 2) that involved one further group of participants engaged in a behavioral match-to-sample task involving the same two-size upright face stimuli of Experiment 1 to test the hypothesis that the two categories of faces (perceived as closer and perceived as more distant) could be more or less easily identifiable. Results of Experiment 2 revealed that face stimuli of the two sizes could be equally identifiable both in terms of accuracy and RTs, supporting the view that the critical factor triggering differential empathic reactions in the two groups of participants in Experiment 1 was not related to the likelihood of identifying the faces of the two sizes. We have to admit that this conclusion should be taken with caution because of the ceiling effect observed with regard to the accuracy level; however, we believe that the observation that also RTs, that are characterized by a more meaningful variation, did not differ between the two sizes conditions provide additional support in favor of our interpretation. It is important to stress that this whole pattern of findings does not imply that an individuation mechanism may not be preferred for faces perceived as closer relative to those perceived as more distant, but rather that the implementation of this mechanism, rather than that of categorization, does not seem to be a direct consequence of the ease/difficulty of identifying faces.

We confess that we cannot rule out the possibility that the size of the faces per se (rather than distance perception) have produced those observed modulations in neural empathic reactions. Nevertheless, we believe this is unlikely since each face was neutrally or painfully stimulated by a tool that was proportional in size to the stimulated face, so the tool provided a contextual cue that participants could use to estimate distance. The findings that the two groups of participants were equally accurate and fast in deciding whether the faces were painfully or neutrally stimulated (Experiment 1) and in discriminating faces of the two sizes (Experiment 2) strongly support the idea that it was not the size per se the key modulator factor of the empathic reactions but rather the perceived distance of the faces. Moreover, as already discussed in the Introduction section, for stimuli whose size is known and familiar to an observer, their size and the retinal image size are sufficient indications to induce an estimate of physical distance (see, e.g., Gogel, 1998).

Although the perception of distance has been proved a fundamental modulator of interpersonal processes, including empathy for pain as demonstrated in the present work, the underlying mechanism is not well understood. At least two classes of theories - that are not mutually exclusive - could account for this modulatory effect, i.e., the Construal Level Theory (CLT; Trope et al., 2007) and the Embodied Cognition Theory (see, e.g., Gallese, 2005; Dijkstra et al., 2007; Niedenthal, 2007; 
Goldman and de Vignemont, 2009; Caruana and Borghi, 2013). The first theoretical approach suggests that as the physical, temporal, social and psychological distance between an individual and an event, an object, or even a person or a group of people increases, not only the salience and perceived relevance diminish (e.g., Latané, 1981; Latané et al., 1995; Williams and Bargh, 2008), but also mental representations of events, objects and other people profoundly change so that as the distance increases, the degree of abstraction of mental representations also increases (e.g., Henderson et al., 2011). Notably, Williams and Bargh (2008) observed that among all of these different types of distances, physical distance is a sort of ontogenetic precursor of all of other types, "the foundation for the later-developed concept of psychological distance" (Williams and Bargh, 2008). Interestingly, this idea dovetails nicely with the evidence provided by the fMRI study by Yamakawa et al. (2009) presented in a previous paragraph suggesting a common neural underpinning for both psychological and physical distance representations in the parietal cortex. Moreover, in line with both the CLT and the experimental evidence provided by the present study, the previous work by Williams and Bargh (2008) had shown, through the implementation of 4 experiments, that when people are exposed to cues of physical distance these can have a moderating effect on their emotional experience, for instance by modulating the degree of emotional attachment to family members or by reducing the level of emotional distress to the vision of violent media. These results converge with the finding that physical distance can therefore also play an important role in moderating an observer's empathic reaction toward others' pain.

According to the theories of Embodied Cognition, most of the cognitive processes depend, reflect, or are influenced by the body control systems (e.g., Caruana and Borghi, 2013). Cognition would therefore be inextricably linked to the body and to its relation with the environment, and it would not be based on abstract and amodal representations. At least three different interpretations of how embodiment might influence cognition have been proposed (see Goldman and de Vignemont, 2009). According to a first interpretation, the body anatomy itself would play a role in cognition, precisely because of the anatomical characteristics of the different body parts. A second interpretation considers how the actions produced by the body can have a deep influence on cognitive processes (e.g., Dijkstra et al., 2007; Niedenthal, 2007); for example, posture and facial expressions could influence the way people remember, discriminate between different categories of stimuli, and could even influence their emotional state. A third interpretation of embodiment, proposed and termed by Gallese (2005) Embodied Simulation, refers to the role that mental representations involving the body can have on cognition. This last interpretation of embodiment is strongly associated with the construct of empathy, and several authors, more or less explicitly, have suggested that embodied simulation/mirroring mechanisms are at the basis of the most automatic component of empathy (Gallese and Goldman, 1998; Gallese, 2003, 2008; Gallese et al., 2006; Csibra, 2008; Hickok, 2009; Singer and Lamm, 2009; Lamm and Singer, 2010; Uithol et al., 2011; but see also Lamm and Majdandžić, 2015). Caggiano et al. (2009) have shown the existence of a subpopulation of mirror neurons in the premotor cortex of rhesus monkeys whose activity is modulated on the basis of the spatial position in which the observed action occurs; in particular, half of these neurons are activated preferentially for the monkey's peripersonal space while the other half is more responsive for the extrapersonal space. The authors interpreted these fascinating results by suggesting that mirror neurons (and likely, more generally, mirror mechanisms) not only constitute the neural substrate of the "understanding of what others are doing, but also may contribute toward selecting how I might interact with them" (Caggiano et al., 2009). This result could suggest that the neurally instantiated we-centric space (Gallese, 2003) underlying the embodied simulation conceived as the mechanism that mediates our ability to share the meaning of actions, emotions, emotional states with others - might be sensitive to the physical distance that separates the observer and the other individual and to the space of potential interaction between the two, the so-called interaction space, that is the shared reaching space of the two individuals (Nguyen and Wachsmuth, 2011). These findings and observations could allow to predict that even the empathic reactions of an observer could be influenced by the distance that separates her/him from the individual experiencing a particular affective state and that these reactions might be different when the two individuals are within the space of potential interaction or not. We acknowledge that at the moment this second interpretation regarding the mechanism underlying the effect of physical distance in the modulation of empathy is certainly speculative (although intriguing) and will require further research.

Finally, we want to mention that our findings are in line with the evidence reported by Yang et al. (2014) that the efficiency of faces recognition, for both upright and inverted faces, varies as a function of faces size. The authors manipulated faces size between 1 and $10^{\circ}$ of visual angle and demonstrated that only faces larger than $6^{\circ}$ of visual angle are associated with the recruitment of specialized face processes. Additionally, while for faces smaller than $6^{\circ}$ of visual angle (corresponding to a perceived distance of $2 \mathrm{~m}$ ), only a quantitative difference between upright and inverted faces was observed in the recruitment of these processes, for faces larger than $6^{\circ}$ of visual angle the difference was qualitative. The authors note that the distance of $2 \mathrm{~m}$ corresponds to the typical interpersonal distance in the context of conversations and social interactions. In brief, their findings support the notion that faces can be processed either through generic recognition processes or involve specialized face-sensitive processes depending on their perceived distance. Interestingly, the perceived distance of the larger faces used in our study corresponds to the upper limit indicated by Yang and colleagues. Finally, the evidence reported by Yang and colleagues also dovetails nicely with the mechanisms underlying CLT and embodied simulation as discussed in the previous paragraphs.

Lastly, we would like to discuss a few possible limitations of the present study. We implemented a between-subjects design (Experiment 1) that has less statistical power than within-subjects designs; between-subjects designs may also have the disadvantage that results may in part depend on interindividual differences that may then characterize the two 
groups of participants differently. Nevertheless, the withinsubject designs have few disadvantages that in the present experimental context we considered to be more alarming. In particular, the main weakness of within-subject designs is that they can be associated with carryover effects. These include effects of practice and fatigue, but in particular we wanted to avoid the "context effect," namely the effect for which stimuli that are perceived/evaluated in an experimental condition can alter how they are perceived/evaluated in a subsequent experimental condition. Obviously this possible effect could have greatly reduced if not eliminated the effects related to the manipulation of the perceived distance. Furthermore, a within-subjects manipulation of the variable relative to the size of the faces would have required doubling the number of trials for each participant in order to guarantee a sufficient signal-to-noise ratio, inevitably producing fatigue with potential electrophysiological effects. We have, however, tried to make the two groups homogeneous by age and gender, two of the variables that could have an impact on participants' empathy (for the age variable see, e.g., Schieman, 2000; Phillips et al., 2002) but see also Grühn et al., 2008; for the gender variable see, e.g., Eisenberg and Lennon, 1983; Cohn, 1991; Feingold, 1994; Brown, 2001; O’Brien et al., 2013; Thompson and Voyer, 2014; but see also Lamm et al., 2007 for contrasting findings).

Furthermore, in the present investigation each experimental group consisted mostly of female participants. Previous studies, as briefly mentioned above, suggested that women's empathy might be greater than that of men and therefore the present results might not be straightaway generalizable to the entire population. Nevertheless, we note that precisely because of the greater empathic abilities found in women in previous studies, the ample reduction of the neural empathic response observed for the faces perceived as more distant is even more reliable.

Finally, we would like to briefly discuss about the statistically null triple interaction between stimulation of face stimuli, physical distance and orientation. A significant triple interaction would probably have further corroborated our conclusions that the perceived distance of someone in conditions of physical suffering is an important modulator of the observer's neural empathic response. However, it is important to underline, as already briefly mentioned in the Introduction, that there are no previous studies, at least to our knowledge, that have directly tested empathic responses for inverted faces. In this vein, our results suggest that inverted faces may still be associated with a neural empathic response although we cannot rule out the possibility that this null result was due to an insufficient

\section{REFERENCES}

Amodio, D. M., and Frith, C. D. (2006). Meeting of minds: the medial frontal cortex and social cognition. Nat. Rev. Neurosci. 7, 268-277. doi: 10.1038/nrn1884

Argyle, M., and Dean, J. (1965). Eye-contact, Distance and Affiliation. Sociometry 28, 289-304. doi: 10.2307/2786027

Astolfi, L., Cincotti, F., Mattia, D., Babiloni, C., Carducci, F., Basilisco, A., et al. (2005). Assessing cortical functional connectivity by linear inverse estimation statistical power. On the other hand, in our opinion, the most striking and interesting finding of the present study is that linked to the interaction between stimulation of face stimuli, and physical distance, which support the conclusion that the perceived distance is an important factor able to modulate observer's empathy. To note, physical distance did not interact with orientation, narrowing the impact of physical distance on how the brain process painful vs. neutral stimulations (but not other characteristics of the faces such as their orientation).

In conclusion, in the present investigation we provided evidence that also the physical distance between an observer and another individual in a particular affective state - such that induced by physical pain - is a decisive factor for the modulation of an empathic reaction in the observer. This evidence provides an important insight into the framework of knowledge on factors capable of shaping empathy, and it is certainly important also in relation to the evidence suggesting a strong link between representations, also in neural terms, of physical and psychological distance. Although it is obvious that in everyday life situations it is not possible to establish in advance the physical distance between an observer and someone subjected to physical pain (given the unpredictability of such situations), the evidence on the importance of physical distance in modulating an empathic reaction could be fundamental for psychotherapy, clinical and medical contexts, in which psychotherapists, doctors and health professionals could use this knowledge to favor or not, as appropriate, an empathic reaction in themselves and in their patients.

\section{ETHICS STATEMENT}

All procedures performed in the study involving human participants were conducted in accordance with the ethical standards of the institutional and national research committee and with the 1964 Helsinki Declaration and its later amendments or comparable ethical standards. Written informed consent was obtained from all participants included in the study.

\section{AUTHOR CONTRIBUTIONS}

PS developed the study concept. All the authors contributed to the study design. ASL, FM, and IR performed the testing and data collection. PS and ASL performed the data analysis and interpreted the data. PS and ASL drafted the manuscript. All the authors approved the final version of the manuscript for submission.

and directed transfer function: simulations and application to real data. Clin. Neurophysiol. 116, 920-932. doi: 10.1016/j.clinph.2004.10.012

Avenanti, A., Sirigu, A., and Aglioti, S. M. (2010). Racial bias reduces empathic sensorimotor resonance with other-race pain. Curr. Biol. 20, 1018-1022. doi: 10.1016/j.cub.2010.03.071

Blair, R. J. R. (2005). Responding to the emotions of others: dissociating forms of empathy through the study of typical and psychiatric populations. Conscious. Cogn. 14, 698-718. doi: 10.1016/j.concog.2005.06.004 
Brewer, M. B. (1988). "A dual process model of impression formation," in A Dual Process Model of Impression Formation, eds T. K. Srull and R. S. Wyer Jr (Hillsdale, NJ: Lawrence Erlbaum Associates, Inc.), 1-36.

Brown, N. (2001). Edward T. Hall, Proxemic Theory, 1966. CSISS Classics. $\iota$ Oakland, CA: University of California.

Caggiano, V., Fugassi, L., Rizzolatti, G., Thier, P., and Casile, A. (2009). Mirror neurons differentially encode the peripersonal and extrapersonal space of monkeys. Science 249, 1668-1672. doi: 10.1126/science.1166818

Caruana, F., and Borghi, A. M. (2013). Embodied cognition: una nuova psicologia. Giornale Italiano Di Psicologia 1, 23-48.

Cohn, L. D. (1991). Sex differences in the course of personality development: a meta-analysis. Psychol. Bull. 109, 252-266. doi: 10.1037/0033-2909.109.2.252

Contreras-Huerta, L. S., Baker, K. S., Reynolds, K. J., Batalha, L., and Cunnington, R. (2013). Racial bias in neural empathic responses to pain. PLoS One 8:e84001. doi: 10.1371/journal.pone.0084001

Contreras-Huerta, L. S., Hielscher, E., Sherwell, C. S., Rens, N., and Cunnington, R. (2014). Intergroup relationships do not reduce racial bias in empathic neural responses to pain. Neuropsychologia 64, 263-270. doi: 10.1016/J. NEUROPSYCHOLOGIA.2014.09.045

Csibra, G. (2008). Goal attribution to inanimate agents by 6.5 -month-old infants. Cognition 107, 705-717. doi: 10.1016/j.cognition.2007.08.001

Dapretto, M., Davies, M. S., Pfeifer, J. H., Scott, A. A., Sigman, M., Bookheimer, S. Y., et al. (2006). Understanding emotions in others: mirror neuron dysfunction in children with autism spectrum disorders. Nat. Neurosci. 9, 28-30. doi: $10.1038 / \mathrm{nn} 1611$

Davis, M. H. (1983). A mulitdimensional approach to individual differences in empathy. J. Pers. Soc. Psychol. 44, 113-126. doi: 10.1037/0022-3514.44.1.113

Decety, J. (2011). The neuroevolution of empathy. Ann. N. Y. Acad. Sci. 1231, 35-45. doi: 10.1111/j.1749-6632.2011.06027.x

Decety, J., and Jackson, P. L. (2004). The functional architecture of human empathy. Behav. Cogn. Neurosci. Rev. 3, 71-100. doi: 10.1177/ 1534582304267187

Decety, J., and Jackson, P. L. (2006). A social - neuroscience perspective on empathy. Curr. Dir. Psychol. Sci. 15, 54-58. doi: 10.1111/j.0963-7214.2006. 00406.x

Decety, J., and Lamm, C. (2007). The role of the right temporoparietal junction in social interaction: how low-level computational processes contribute to meta-cognition. Neuroscientist 13, 580-593. doi: 10.1177/107385840730 4654

Decety, J., and Svetlova, M. (2012). Putting together phylogenetic and ontogenetic perspectives on empathy. Dev. Cogn. Neurosci. 2, 1-24. doi: 10.1016/j.dcn.2011. 05.003

Decety, J., Yang, C. Y., and Cheng, Y. (2010). Physicians down-regulate their pain empathy response: an event-related brain potential study. Neuroimage 50, 1676-1682. doi: 10.1016/j.neuroimage.2010.01.025

Dijkstra, K., Kaschak, M. P., and Zwaan, R. A. (2007). Body posture facilitates retrieval of autobiographical memories. Cognition 102, 139-149. doi: 10.1016/j. cognition.2005.12.009

Donchin, E. (1981). Surprise!... surprise? Psychophysiology 18, 493-513. doi: 10. 1111/j.1469-8986.1981.tb01815.x

Donchin, E., and Coles, M. G. H. (1988). Is the P300 component a manifestation of context updating? Behav. Brain Sci. 11, 357-374. doi: 10.1017/ S0140525X00058027

Eisenberg, N., and Lennon, R. (1983). Sex differences in empathy and related capacities. Psychol. Bull. 94, 100-131. doi: 10.1037/0033-2909.94.1.100

Fan, Y., Duncan, N. W., de Greck, M., and Northoff, G. (2011). Is there a core neural network in empathy? An fMRI based quantitative metaanalysis. Neurosci. Biobehav. Rev. 35, 903-911. doi: 10.1016/j.neubiorev.2010. 10.009

Fan, Y., and Han, S. (2008). Temporal dynamic of neural mechanisms involved in empathy for pain: an event-related brain potential study. Neuropsychologia 46, 160-173. doi: 10.1016/j.neuropsychologia.2007.07.023

Feingold, A. (1994). Gender differences in personality: a meta-analysis. Psychol. Bull. 116, 429-456. doi: 10.1080/10508422.2011.585591

Fiske, S. T., and Neuberg, S. L. (1990). A continuum of impression formation, from category-based to individuating processes: influences of information and motivation on attention and interpretation. Adv. Exp. Soc. Psychol. 23, 1-74. doi: 10.1016/S0065-2601(08)60317-2
Gallese, V. (2003). The roots of empathy: the shared manifold hypothesis and the neural basis of intersubjectivity. Psychopathology 36, 171-180. doi: 10.1159/ 000072786

Gallese, V. (2005). Embodied simulation: from neurons to phenomenal experience. Phenomenol. Cogn. Sci. 4, 23-48. doi: 10.1007/s11097-005-4737-z

Gallese, V. (2008). Embodied simulation: from mirror neuron systems to interpersonal relations. Empathy Fairness 278, 3-12. doi: 10.1002/ 9780470030585.ch2

Gallese, V., and Goldman, A. (1998). Mirror neurons and the mind-reading. Trens Cogn. Sci. 2, 493-501. doi: 10.1016/S1364-6613(98)01262-5

Gallese, V., Migone, P., and Eagle, M. N. (2006). La simulazione incarnata: i neuroni specchio, le basi neurofisiologiche dell'intersoggettività ed alcune implicazioni per la psicoanalisi. Psicoterapia E Scienze Umane 40, 543-580.

Gogel, W. C. (1998). An analysis of perceptions from changes in optical size. Percept. Psychophys. 60, 805-820. doi: 10.3758/BF03206064

Goldman, A. I., and de Vignemont, F. (2009). Is social cognition embodied? Trends Cogn. Sci. 13, 154-159. doi: 10.1016/j.tics.2009.01.007

Grühn, D., Rebucal, K., Diehl, M., and Labouvie-Vief, G. (2008). Empathy across the adult lifespan: longitudinal and experience- sampling findings. Emotion 8 , 753-765. doi: $10.1037 / \mathrm{a} 0014123$

Hall, E. T. (1963). System notation proxemic. Am. Anthropol. 65, 1003-1025. doi: 10.1525/aa.1963.65.5.02a00020

Hall, E. T. (1966). The Hidden Dimension. Garden City, NY: Anchor Books.

Hall, E. T. (1969). The Silent Language. Garden City, NY: Anchor Books.

Hall, E. T., Birdwhistell, R. L., Bock, B., Bohannan, P., Richard, A., Durbin, M., et al. (1968). Proxemics [and comments and replies]. Curr. Anthropol. 9, 83-108. doi: $10.1086 / 200975$

Harris, L. T., and Fiske, S. T. (2006). Dehumanizing the lowest of the low. Psychol. Sci. 17, 847-853. doi: 10.1111/j.1467-9280.2006.01793.x

Hayduk, L. A. (1983). Personal space: where we now stand. Psychol. Bull. 94, 293-335. doi: 10.1037/0033-2909.94.2.293

Hein, G., Silani, G., Preuschoff, K., Batson, C. D., and Singer, T. (2010). Neural responses to ingroup and outgroup members' suffering predict individual differences in costly helping. Neuron 68, 149-160. doi: 10.1016/j.neuron.2010. 09.003

Henderson, M. D., Wakslak, C. J., Fujita, K., and Rohrbach, J. (2011). Construal level theory and spatial distance implications for mental representation, judgment, and behavior. Soc. Psychol. 42, 165-173. doi: 10.1027/1864-9335/ a000060

Hickok, G. (2009). Eight problems for the mirror neuron theory of action: understanding in monkeys and humans. J. Cogn. Neurosci. 21, 1229-1243. doi: 10.1162/jocn.2009.21189.Eight

Lakoff, G., and Mark, J. (1999). Book review: philosophy in the flesh: the embodied mind and its challenge to western thought. Metaphor Symb. 15, 267-274. doi: 10.1207/S15327868MS1504-7

Lakoff, G., and Johnson, M. (1980). Conceptual metaphor in everyday language. J. Philos. 77, 453-486. doi: 10.2307/2025464

Lamm, C., Batson, C. D., and Decety, J. (2007). The neural substrate of human empathy: effects of perspective- taking and cognitive appraisal. J. Cogn. Neurosci. 19, 42-58. doi: 10.1162/jocn.2007.19.1.42

Lamm, C., and Majdandžić, J. (2015). The role of shared neural activations, mirror neurons, and morality in empathy - a critical comment. Neurosci. Res. 90, 15-24. doi: 10.1016/j.neures.2014.10.008

Lamm, C., and Singer, T. (2010). The role of anterior insular cortex in social emotions. Brain Struct. Funct. 214,579-591. doi: 10.1007/s00429-010-0251-3

Latané, B. (1981). The psychology of social impact. Am. Psychol. 36, 343-356. doi: 10.1037/0003-066X.36.4.343

Latané, B., Liu, J. H., Nowak, A., Bonevento, M., and Zheng, L. (1995). Distance matters: physical space and social impact. Pers. Soc. Psychol. Bull. 21, 795-805. doi: $10.1177 / 0146167295218002$

Leder, H., and Bruce, V. (2000). When inverted faces are recognized: the role of configural information in face recognition. Q. J. Exp. Psychol. A 53(2), 513-536. doi: $10.1080 / 713755889$

Li, W., and Han, S. (2010). Perspective taking modulates event-related potentials to perceived pain. Neurosci. Lett. 469, 328-332. doi: 10.1016/j.neulet.2009.12.021

Lockwood, P. L. (2016). The anatomy of empathy: vicarious experience and disorders of social cognition. Behav. Brain Res. 311, 255-266. doi: 10.1016/j. bbr.2016.05.048 
Meconi, F., Vaes, J., and Sessa, P. (2015). On the neglected role of stereotypes in empathy toward other-race pain. Soc. Neurosci. 10, 1-6. doi: 10.1080/17470919. 2014.954731

Naito, E., Scheperjans, F., Eickhoff, S. B., Amunts, K., Roland, P. E., Zilles, K., et al. (2008). Human superior parietal lobule is involved in somatic perception of bimanual interaction with an external object. J. Neurophysiol. 99, 695-703. doi: $10.1152 /$ jn. 00529.2007

Neggers, S. F., Van der Lubbe, R. H., Ramsey, N. F., and Postma, A. (2006). Interactions between ego- and allocentric neuronal representations of space. Neuroimage 31, 320-331. doi: 10.1016/J.NEUROIMAGE.2005.12.028

Newell, F. N., and Bülthoff, H. H. (2002). Categorical perception of familiar objects. Cognition 85, 113-143. doi: 10.1016/S0010-0277(02)00104-X

Nguyen, N., and Wachsmuth, I. (2011). From body space to interaction space: modeling spatial cooperation for virtual humans. Agents Multiagent Syst. 3, 2-6.

Niedenthal, P. M. (2007). Embodying emotion. Science 316, 1002-1005. doi: 10. $1126 /$ science. 1136930

O’Brien, E., Konrath, S. H., Grühn, D., and Hagen, A. L. (2013). Empathic concern and perspective taking: linear and quadratic effects of age across the adult life span. J. Gerontol. B Psychol. Sci. Soc. Sci. 68, 168-175. doi: 10.1093/geronb/ gbs055

Philip, R. C., Dauvermann, M. R., Whalley, H. C., Baynham, K., Lawrie, S. M., and Stanfield, A. C. (2012). A systematic review and meta-analysis of the fMRI investigation of autism spectrum disorders. Neurosci. Biobehav. Rev. 36, 901-942. doi: 10.1016/j.neubiorev.2011.10.008

Phillips, L. H., MacLean, R. D. J., and Allen, R. (2002). Age and the understanding of emotions: neuropsychological and sociocognitive perspectives. J. Gerontol. B Psychol. Sci. Soc. Sci. 57, 526-530. doi: 10.1093/geronb/57.6.P526

Preston, S. D., and de Waal, F. B. M. (2002). Empathy: its ultimate and proximate bases. Behav. Brain Sci. 25, 1-20. doi: 10.1017/S0140525X02000018

Rameson, L. T., and Lieberman, M. D. (2009). Empathy: a social cognitive neuroscience approach. Soc. Pers. Psychol. Compass 3, 94-110. doi: 10.1111/j. 1751-9004.2008.00154.x

Rapcsak, S. Z., Ochipa, C., Anderson, K. C., and Poizner, H. (1995). Progressive ideomotor apraxia - evidence for a selective impairment of the action production system. Brain Cogn. 27, 213-236. doi: 10.1006/brcg.1995.1018

Rizzolatti, G., and Sinigaglia, C. (2010). The functional role of the parieto-frontal mirror circuit: interpretations and misinterpretations. Nat. Rev. Neurosci. 11, 264-274. doi: 10.1038/nrn2805

Roland, P. E., Larsen, B., Lassen, N. A., and Skinhoj, E. (1980). Supplementary motor area and other cortical areas in organization of voluntary movements in man. J. Neurophysiol. 43, 118-136. doi: 10.1152/jn.1980.43.1.118

Sakata, H., Shibutani, H., and Kawano, K. (1980). Spatial properties of visual fixation neurons in posterior parietal association cortex of the monkey. J. Neurophysiol. 43, 1654-1672. doi: 10.1152/jn.1980.43.6.1654

Saxe, R., and Kanwisher, N. (2003). People thinking about thinking peopleThe role of the temporo-parietal junction in "theory of mind." Neuroimage 19, 1835-1842. doi: 10.1016/S1053-8119(03)00230-1

Schieman, S. (2000). The personal and social links between age and selfreported empathy author(s): scott schieman and karen van gundy source: social psychology quarterly. Am. Sociol. Assoc. St. Soc. Psychol. Q. 63, 152-174. doi: $10.2307 / 2695889$

Sessa, P., Luria, R., Verleger, R., and Dell'Acqua, R. (2007). P3 latency shifts in the attentional blink: further evidence for second target processing postponement. Brain Res. 1137, 131-139. doi: 10.1016/j.brainres.2006.12.066

Sessa, P., and Meconi, F. (2015). Perceived trustworthiness shapes neural empathic responses toward others' pain. Neuropsychologia 79, 97-105. doi: 10.1016/j. neuropsychologia.2015.10.028

Sessa, P., Meconi, F., Castelli, L., and Dell'Acqua, R. (2014a). Taking one's time in feeling other-race pain: an event-related potential investigation on the time-course of cross-racial empathy. Soc. Cogn. Affect. Neurosci. 9, 454-463. doi: 10.1093/scan/nst003

Sessa, P., Meconi, F., and Han, S. (2014b). Double dissociation of neural responses supporting perceptual and cognitive components of social cognition: evidence from processing of others' pain. Sci. Rep. 4:7424. doi: 10.1038/srep07424

Shamay-Tsoory, S. G., Aharon-Peretz, J., and Perry, D. (2009). Two systems for empathy: a double dissociation between emotional and cognitive empathy in inferior frontal gyrus versus ventromedial prefrontal lesions. Brain 132, 617-627. doi: 10.1093/brain/awn279

Sheng, F., and Han, S. (2012). Manipulations of cognitive strategies and intergroup relationships reduce the racial bias in empathic neural responses. Neuroimage 61, 786-797. doi: 10.1016/j.neuroimage.2012.04.028

Sheng, F., Han, X., and Han, S. (2016). Dissociated neural representations of pain expressions of different races. Cereb. Cortex 26, 1221-1233. doi: 10.1093/cercor/ bhu314

Singer, T., and Lamm, C. (2009). The social neuroscience of empathy. Ann. N. Y. Acad. Sci. 1156, 81-96. doi: 10.1111/j.1749-6632.2009.04418.x

Singer, T., Seymour, B., O’Doherty, J., Dolan, R. J., Kaube, H., and Frith, C. D. (2004). Empathy for pain involves the affective but not sensory components of pain. Science 303, 1157-1162. doi: 10.1126/science.1093535

Singer, T., Seymour, B., O’Doherty, J. P., Stephan, K. E., Dolan, R. J., and Frith, C. D. (2006). Empathic neural responses are modulated by the perceived fairness of others. Nature 439, 466-469. doi: 10.1038/nature04271

Thompson, A. E., and Voyer, D. (2014). Sex differences in the ability to recognise non-verbal displays of emotion: a meta-analysis. Cogn. Emot. 28, 1164-1195. doi: 10.1080/02699931.2013.875889

Trope, Y., Liberman, N., and Wakslak, C. (2007). Construal level and psychological distances: effects on representation, prediction, evaluation, and behavior. J. Consum. Psychol. 17, 83-95. doi: 10.1016/S1057-7408(07)70013-X.Construal

Uithol, S., van Rooij, I., Bekkering, H., and Haselager, P. (2011). Understanding motor resonance. Soc. Neurosci. 6, 388-397. doi: 10.1080/17470919.2011. 559129

Verleger, R. (1988). Event-related potentials and cognition: a critique of the context updating hypothesis and an alternative interpretation of P3. Behav. Brain Sci. 11, 343-356. doi: 10.1017/S0140525X00058015

Wagner, D. D., Kelley, W. M., and Heatherton, T. F. (2011). Individual differences in the spontaneous recruitment of brain regions supporting mental state understanding when viewing natural social scenes. Cereb. Cortex 21, 2788-2796. doi: 10.1093/cercor/bhr074

Williams, L. E., and Bargh, J. A. (2008). Experiencing physical warmth promotes interpersonal warmth lawrence. Science 322, 606-607. doi: 10.1126/science. 1162548.Experiencing

Xu, X., Zuo, X., Wang, X., and Han, S. (2009). Do you feel my pain? Racial group membership modulates empathic neural responses. J. Neurosci. 29, 8525-8529. doi: 10.1523/JNEUROSCI.2418-09.2009

Yamakawa, Y., Kanai, R., Matsumura, M., and Naito, E. (2009). Social distance evaluation in human parietal cortex. PLoS One 4:e4360. doi: 10.1371/journal. pone.0004360

Yang, N., Shafai, F., and Oruc, I. (2014). Size determines whether specialized expert processes are engaged for recognition of faces. J. Vis. 14:17. doi: 10.1167/ 14.8.17

Young, A. W., Rowland, D., Calder, A. J., Etcoff, N. L., Seth, A., and Perrett, D. I. (1997). Facial expression megamix: tests of dimensional and category accounts of emotion recognition. Cognition 63, 271-313. doi: 10.1016/S0010-0277(97) 00003-6

Zaki, J. (2013). Neural sources of empathy: an evolving story. In Understanding Other Minds: Perspectives From Developmental Social Neuroscience. eds S Baron-Cohen, H Tager-Flusberg, and M Lombardo (Oxford: Oxford University press, 214-232). doi: 10.1093/acprof:oso/9780199692972.003.0013

Zaki, J., and Ochsner, K. (2012). The neuroscience of empathy: progress, pitfalls and promise. Nat. Neurosci. 15, 675-680. doi: 10.1038/nn.3085

Conflict of Interest Statement: The authors declare that the research was conducted in the absence of any commercial or financial relationships that could be construed as a potential conflict of interest.

Copyright (c) 2018 Schiano Lomoriello, Meconi, Rinaldi and Sessa. This is an openaccess article distributed under the terms of the Creative Commons Attribution License (CC BY). The use, distribution or reproduction in other forums is permitted, provided the original author(s) and the copyright owner(s) are credited and that the original publication in this journal is cited, in accordance with accepted academic practice. No use, distribution or reproduction is permitted which does not comply with these terms. 